\title{
10. CALCAREOUS SPHERULES FROM THE ALBIAN OF DSDP LEG 40, SITE 363
}

\author{
Hans M. Bolli, Department of Geology, Swiss Federal Institute of Technology, Zurich, \\ and University of Zurich, Switzerland
}

\section{INTRODUCTION}

Calcisphaerulidae, mostly spherically shaped Pithonella cf. sphaerica, occur in very large numbers in the Albian Cores 26-39 of the Leg 40 Site 363, drilled on Walvis Ridge in the South Atlantic. In the numerous samples investigated from this interval (Bolli, this volume) most of the $44-63 \mu \mathrm{m}$ fractions consist almost exclusively of Calcisphaerulidae. Often they are also abundant in the 63-177 $\mu \mathrm{m}$ fraction where, however, their size is restricted to not more than about $90 \mu \mathrm{m}$.

A sample taken in Sample 31-1, 124-126 cm, was found to be equally rich in spherules of about the same size as the Calcisphaerulidae from samples taken above and below this level. Closer examination however showed that almost all of them are not hollow and formed by one or more layers as is typical for the Calcisphaerulidae, but consist of more or less densely arranged radial crystals filling the whole spherule.

In comparison with forms described as fossils, the spherules come closest to some Globochaete alpina specimens of Colom (1955). On Plate 3, Figures 17, 19, and 22 he shows more or less spherical specimens filled with radially arranged crystals, similar to those discussed here. The majority of the Globochaete alpina specimens however, figured by Colom and also those originally given by Lombard (1945), are of different shapes and are also smaller in size (about $30 \mu \mathrm{m}$ ).

The nature of Globochaete alpina, in particular the specimens with a distinct radial arrangement of crystals as illustrated by Colom, still awaits clarification. Like the spherules described here, they also may be recrystallized forms.

Some indications suggest that the spherules are replacements of Calcisphaerulidae. Two distinct types of spherules, with intermediate forms, can clearly be distinguished, which may represent a younger and an older growth stage. One, probably the younger of the two, consists of slender, radially arranged very long crystals in a loose arrangement throughout. The other, comprising the majority of the specimens, consists of tightly packed crystals in the central part, which become progressively more loosely arranged towards the periphery.

\section{DESCRIPTION}

The sediment in which the spherules occur is a light gray marly chalk with cyclical bedding, locally intense burrowing, and some winnowing. Moderately preserved calcareous nannoplankton and planktonic and calcareous benthic foraminifers are frequent. To disintegrate the sample, approximately $10 \mathrm{cc}$ of sample material from Sample 31-1, 124-126 cm, was first

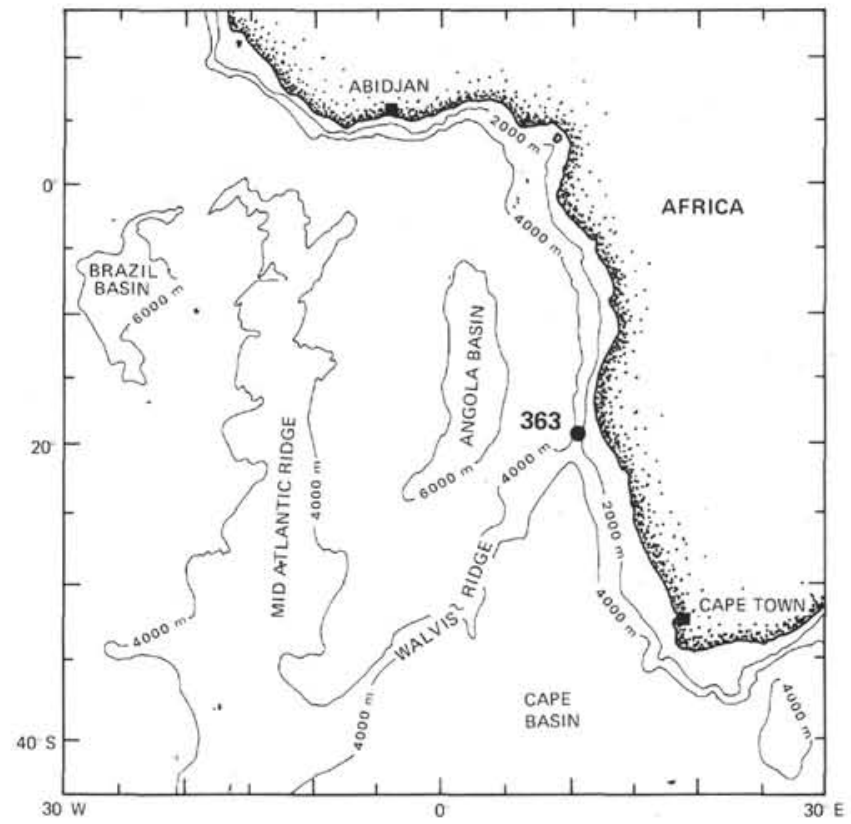

Figure 1. Location of Leg 40 Site 363.

placed in a $20 \% \mathrm{H}_{2} \mathrm{O}_{2}$ solution, then washed through a set of sieves. The spherules make up almost all of the 44-63 $\mu \mathrm{m}$ fraction, with in addition, only scarce Calcisphaerulidae and some mica flakes present. About $50 \%$ of the 63-177 $\mu \mathrm{m}$ fraction also consists of spherules, while planktonic and calcareous benthic foraminifers make up the other $50 \%$. Here, most of the spherules fall into the size range $63 \mu \mathrm{m}$ to about $90 \mu \mathrm{m}$, while the foraminifers are larger, up to $177 \mu \mathrm{m}$. In contrast to the Calcisphaerulidae which occur in floods above and below this level, the spherules are not hollow but are filled in with concentrically arranged radiating elongate crystals.

The spherules of the first type mentioned above, probably the younger of the two, represent about $10 \%$ of the specimens present. They are formed by very long, slender crystals arranged in a loose way and originating from or near the center (Plate 1, Figures 4-12). Groups of crystals may branch out from a central point (Plate 1, Figures 7-11). They often are also bent in a fan or palmate manner (Plate 1, Figure 8 ) or have a tendency towards a spiral arrangement (Plate 1, Figures 5, 6, 10, 11). Rounded knobs on the terminations of the crystals, and along the edges are also present in most crystals (Plate 1, Figures 6, 12). Some of the spherules seem to have a small hollow center (Plate 1, Figures 4, 5, 7) which may be remnants of apertures or hollow interiors of the original Calcisphaerulidae. 
The spherules of the second type, representing with about $70 \%$ the majority of the specimens, have tightly packed crystals in their central part (Plate 2, Figures 26). Here individual crystals are difficult to distinguish. They become progressively more loosely arranged towards the periphery (Plate 2, Figure 7), and appear on the surface of the spherules as individual, radially arranged and distinctly elongate platy crystals with rounded, knob-like terminations. Such rounded knobs may also be present as lateral outgrowths (Plate 2, Figures 10-12).

Though most specimens of the second type are spherical, some have a somewhat irregular form (Plate 2, Figure 3), and a few specimens possess a more or less distinct bispherical shape (Plate 2, Figure 6).

The specimens on Plate 2, Figures 8,9 seem to represent an intermediate stage in crystal density between the two growth stages so far described. About $20 \%$ of the spherules are of this intermediate type.

\section{AGE}

Based on calcareous nannoplankton the age of Core 31 in which the spherules occur has been determined as Eiffellithus turriseiffeli Zone, upper Albian.

\section{MINERALOGY AND CHEMISTRY}

A preliminary $\mathrm{X}$-ray diffraction study was carried out on the sample in question (Sample 31-1, 124-126 $\mathrm{cm}$ ), one sample from Core 29 consisting virtually of Calcisphaerulidae only, and one from a deeper level of Core 31 where dolomite crystals dominate. The 44-63 $\mu \mathrm{m}$ fraction was investigated for all cases. The results are as follows:

Sample 29-1, 71-73 cm, sample consisting of Calcisphaerulidae. X-ray diagnosis: strong predominance (95\%) of stoichiometric calcite with only traces of quartz, feldspar, and other detritals.

Sample $31-1,124-126 \mathrm{~cm}$, sample consisting largely of spherules, with very few Calcisphaerulidae and mica flakes present. X-ray diagnosis: predominance of calcite $(70 \%)$ which in contrast to the Calcisphaerulidae above appears to have a $\mathrm{Mg}$ content of up to $3 \%-5 \%$. Quartz and mica represent about $15 \%$ of the sample; dolomite, trace of feldspars, and unidentified material make up the remaining $15 \%$.

There is a less dominant peak at $2.91 \AA$, indicating a slightly (55\%-57\%) Ca-rich dolomite, poorly ordered without all lattice reflections. Accessory minor unidentified peaks occur at $9.01,8.62,3.85$, and $2.491 \AA$ $\mathrm{d}$-spacings. Further studies are necessary to confirm the nature of these minor possibly important components.

Optical investigation shows that the spherules consisting of radially arranged crystals have a high refractive index and birefringence, showing strong dispersion, also an indication for a carbonate mineralogy.

Sample $31-4,119-124 \mathrm{~cm}$, sample consisting of rhombic crystals and Calcisphaerulidae. X-ray diagnosis: About $50 \%$ dolomite and $30 \%$ calcite. Both calcite and dolomite appear non-stoichiometric showing an excess of about $6 \%-8 \% \mathrm{Ca}$ in the dolomite and $3 \%-5 \% \mathrm{Mg}$ in the calcite. Accessory minerals include a $9.0 \AA$ mica, quartz, and feldspars.
Investigation of some spherules by means of the Energy Dispersive X-ray Analyzer (EDAX) showed the following elements in order of frequency: $\mathrm{Ca}, \mathrm{P}, \mathrm{Cl}$, possibly some $\mathrm{Na}$. These results deviate somewhat from those obtained from the X-ray investiations.

While planktonic foraminifers from the same sample dissolve violently when placed in a $3 \% \mathrm{NaCl}$ solution, the spherules dissolve much more slowly.

\section{POSSIBLE ORIGIN}

$\mathrm{X}$-ray investigations suggest that the rhombic dolomite crystals in Sample 31-4, 119-124 cm may be replacements of Calcisphaerulid tests which originally consisted of calcite, as is the case in Sample 29-1, 71-73 $\mathrm{cm}$. The presence of a low $(3 \%-5 \%) \mathrm{Mg}$ content in the predominantly calcitic spherules of Sample 31-1, 124$126 \mathrm{~cm}$ may be an indication that an exchange of $\mathrm{Mg}$ for $\mathrm{Ca}$ is taking place and that the spherules represent some first stage towards a more complete recrystallization to dolomite such as may be the case in Sample $31-4,119-124 \mathrm{~cm}$.

Plate 2, Figure 1 shows a Pithonella (probably $P$. cf. sphaerica) in the lower left and a fragment of one towards the upper left. The remaining spherules are those described here. Plate 1, Figure 1, shows a Pithonella with strong dissolution effects; its lower portion is beginning to break up. A spherule of the kind described here is sitting on it. Plate 1, Figure 2 shows a Pithonella which appears to be in the progress of being replaced by crystals forming a spherule of radially arranged crystals. Plate 1, Figure 3 is a partial enlargement of Figure 2.

If recrystallization or replacement has occurred, it would be of interest to know the reasons for such processes and under what conditions they took place. Because the size and frequency of the spherules is closely comparable to that of the Calcisphaerulidae occurring in the section above and below the spherule level, it seems the most obvious explanation is that the spherules are completely recrystallized forms of Calcisphaerulidae with the original wall structure replaced by a radial arrangement of crystals. With the presence in the same sample of abundant calcareous nannoplankton and calcareous foraminifers, and also of rare Calcisphaerulidae, it is not clear why most of the Calcisphaerulidae only should have become recrystallized. However, Plate 1, Figures 1-3, which show apparent partial replacements of Pithonellas, seem to provide good evidence for such an interpretation.

The possibility that the spherules are of an organic origin also has to be considered. Because all samples above, below and including this interval were disintegrated in the same way, and because the spherules have a distinctive chemical composition, it is unlikely that we are dealing here with artifacts which formed by a chemical reaction during the laboratory processing of the sample.

\section{DEPOSITORY OF SPECIMENS}

The specimens figured on Plates 1 and 2, and some additional material, are deposited at the Museum of Natural History, Basel, under the numbers C 3399133997. 


\section{ACKNOWLEDGMENTS}

The author wishes to express his gratitude to H.E. Franz for preparing the SEM micrographs and the EDAX determinations, to $\mathrm{K}$. Kelts for carrying out the X-ray investigations, to $W$. Oberholzer for discussing the mineralogical aspects, to J. Neher for commenting on possible organic origins of the spherules, and to J.P. Beckmann for reviewing the manuscript.

\section{REFERENCES}

Colom, G., 1955. Jurassic-Cretaceous pelagic sediments of the western Mediterranean zone and the Atlantic area: Micropaleontology, v. 1, p. 109-124.

Lombard, A., 1945. Attribution de microfossiles du Jurassic supérieur alpin à des chlorophycées (Proto- et Pleurococcacées): Eclog. Geol. Helv., v. 38, p. 163-173. 


\section{PLATE 1}

All illustrated specimens are from Leg 40, Site 363, Sample 31-1, $124-126 \mathrm{~cm}$, and photographed from smear mount C 33991.

Figure $1 \quad$ Pithonella (probably $P$. cf. sphaerica) with aperture, partially broken in its lower part. A spherule with slender, radially arranged crystals covers the top left part of this specimen, where replacement appears to be in progress. $\times 720$.

Figures 2,3 Pithonella with its upper part apparently replaced by crystals forming a spherule. Figure 3 shows a detail of the "boundary area" between the remaining portion of the Pithonella and the slender radially arranged crystals of the spherule replacing it.

2. $\times 840$.

3. $\times 3000$.

Figure 4

Spherule of first type with loosely arranged crystals which probably represents the early growth stage of the second type, where crystals are tightly packed in the center (see Plate 2, Figures 2$6)$. The long slender, radially arranged crystals leave a small aperture-like opening, which may be interpreted as a remnant of a Calcisphaerulidae aperture. $\times 960$.

Figures 5-12 Spherules of the first type. The spherules on Figures 5, 7, 10 appear to be split, making visible their central part. The small holes in Figures 5 and 7 may thus be remnants of the hollow interiors of Calcisphaerulidae. Apparent in all three specimens is the tendency of crystals to branch out from a central point, and form fan-shaped or palmate groups which sometimes tend towards a spiral arrangement (Figure 5). Distinct are the rounded knob-like terminations of the crystals (Figures 6, 12).

5, $7,10 . \times 1200$.

6. Detail of Figure $5, \times 6000$.

8, 9. Details of Figure 7, $\times 3000$.

11. Detail of Figure $10, \times 3000$.

12. Detail of Figure $10, \times 6000$. 
PLATE 1
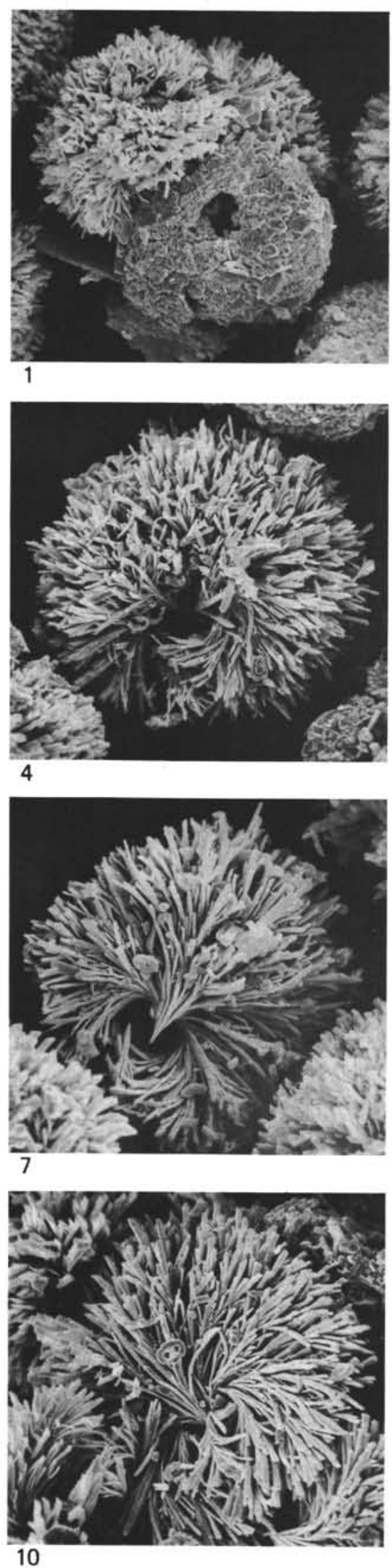
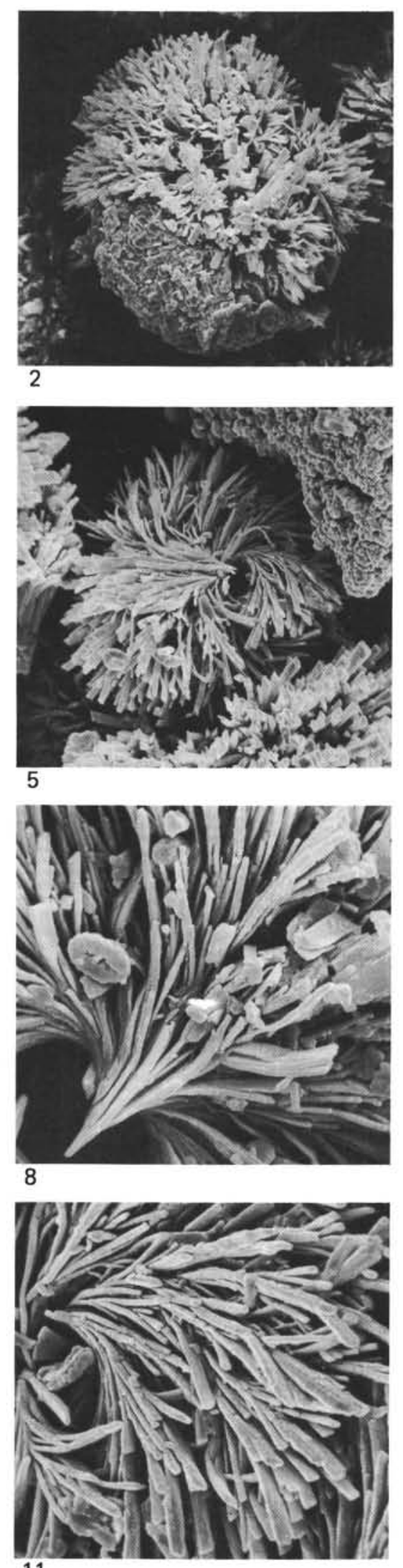

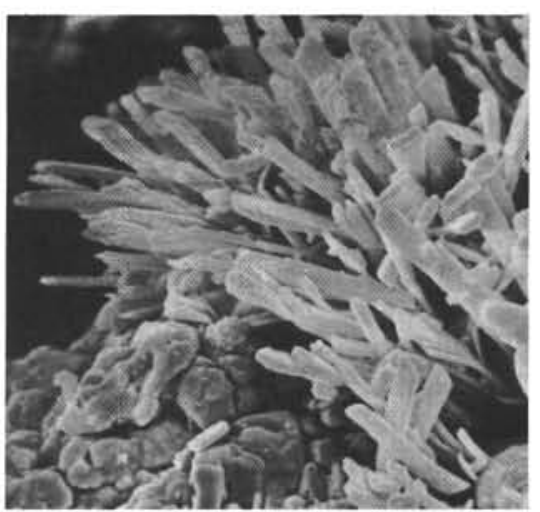

3
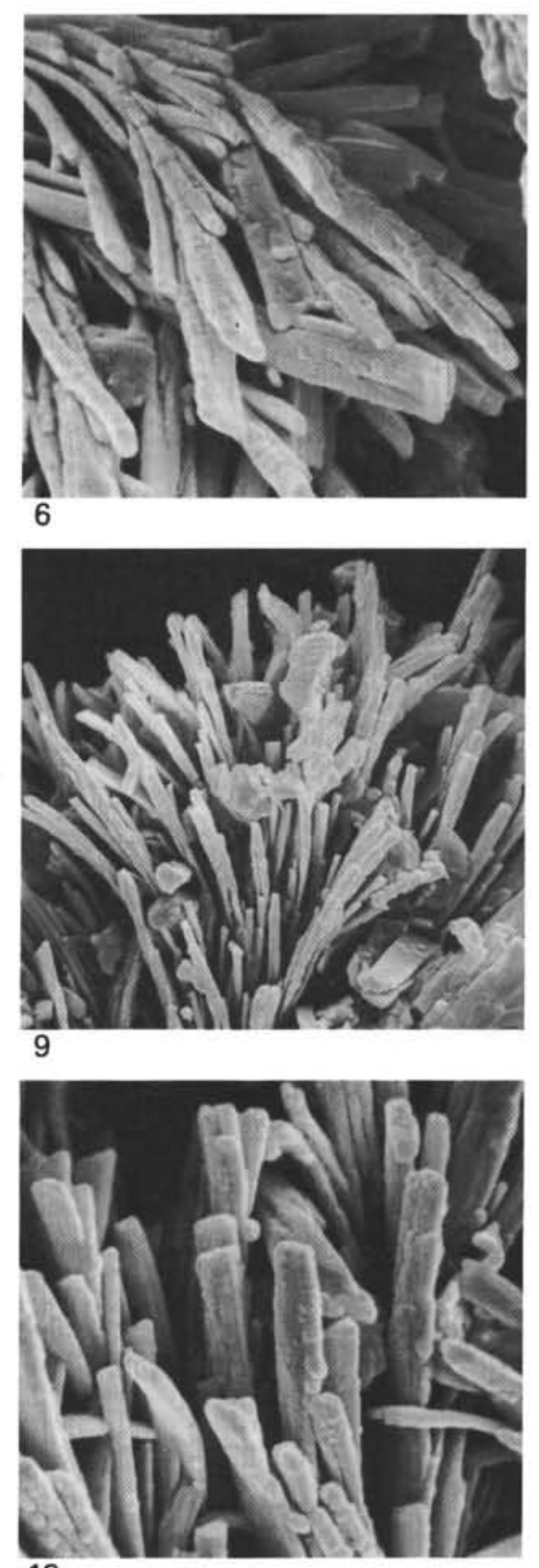

12 


\section{PLATE 2}

All illustrated specimens are from Leg 40, Site 363, Sample $31-1,124-126 \mathrm{~cm}$.

Figure 1 Micrograph showing a number of spherules having both more loosely arranged crystals (similar to those of Plate 1, Figures 4-12) and more tightly packed crystals (this Plate, Figures 2-7 and 10-12). At the lower left is a Pithonella (probably $P$. cf. sphaerica); a broken specimen is also recognizable in the upper left, to the left of a mica flake. $\times 300$. C 33991 .

Figures 2, $\quad$ Spherule of the more densely packed type, with 10-12 Figures 10-12 showing details of the surface. Clearly visible at these greater magnifications are the radially arranged tabular crystals with rounded, knob-like features at terminations and also as lateral outgrowths.

2. $\times 600$, C 33992 .

10. $\times 6000$.

II, $12 . \times 12,000$.

Figure 3 Irregularly shaped spherule of the more densely packed type, $\times 500$. C 33993.

Figures 4, 7 Split spherule, showing concentrical arrangement of crystals, tightly packed in the central part, becoming more loosely arranged towards the periphery. Figure 7 is a detailed view of the less tightly interlocked crystals on the upper right of Figure 4, C 33994.

4. $\times 600$.

7. $\times 3000$.

Figure 5 Split spherule, showing same features as Figure 4, $\times 600$. C 33995.

Figure 6 Bispherical spherule, $\times 500$. C 33996 .

Figures 8,9 Spherule intermediate in appearance between the two described types. Figure 9 shows detail of top left of Figure 8, C 33997.

8. $\times 960$.

9. $\times 6000$. 
PLATE 2
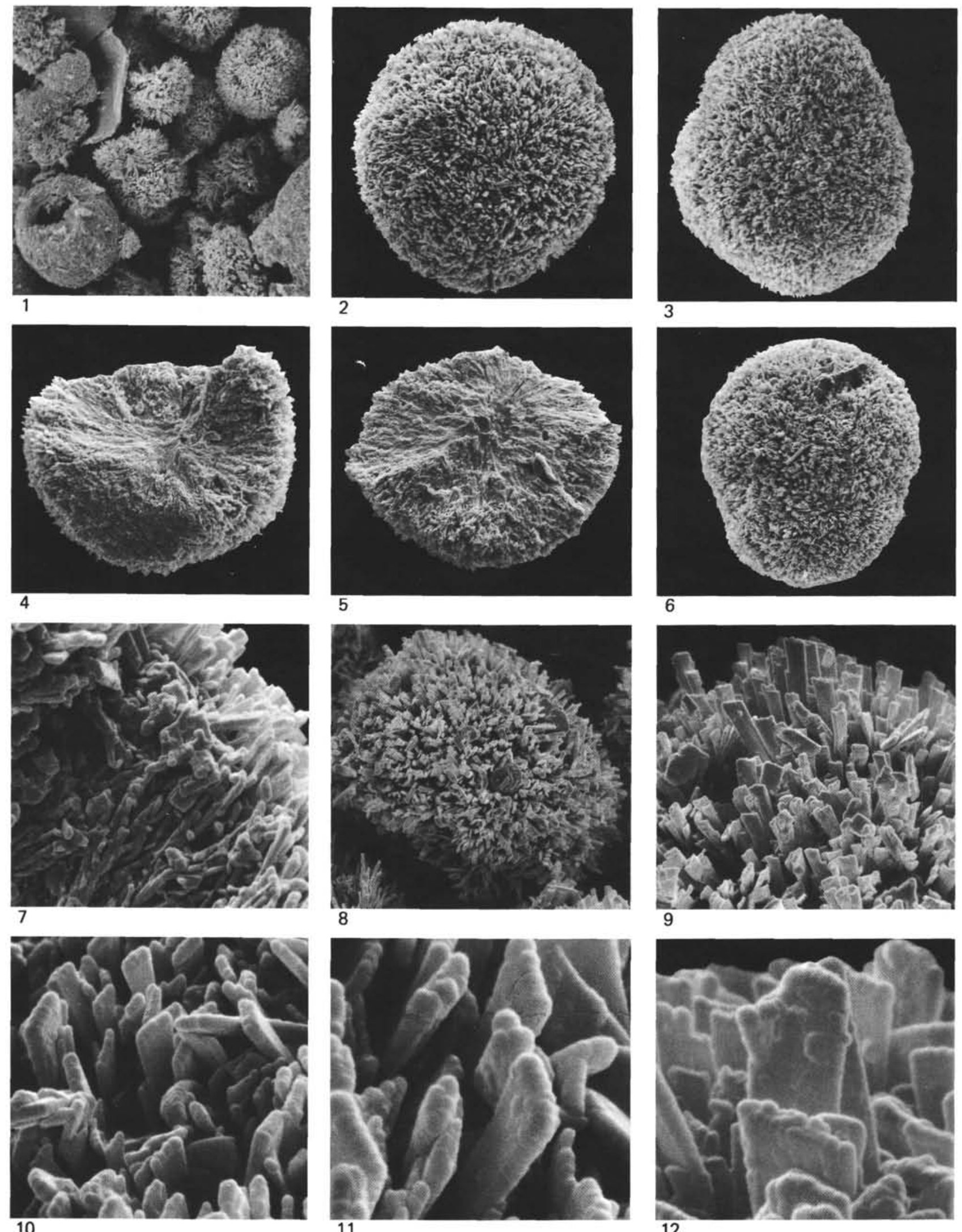

12 